\title{
New dynamic technique for SAC-OCDMA system
}

\begin{abstract}
In this paper a family of novel spreading sequences, called a Multi-Service (MS) code have been proposed for SAC-OCDMA system. The performance of the proposed code is demonstrated using mathematical analysis. Reference to the Bit Error Rate (BER) of 10 -9 MS code supports up to 90 users simultaneously, choosing code weight of 5 when the bit-rate is $622 \mathrm{Mbps}$. Thus, from the results it indicates that MS code does not only preserve the capability of suppressing Multiple Access Interference (MAI), but also improves BER performance due to low cross-correlation $(x)$ between code sequences. (i. e. 0 Ò $\underset{x}{ } 1$ ). Furthermore, the results showed that with lower value of basic users can support larger number of subscribers as well as better performance in terms of acceptable BER.
\end{abstract}

Keyword: Optical code division multiple access (OCDMA); Spectral amplitude coding (SAC); Multiple access interference (MAI) 